\title{
Trends in Cytomorphological Study of Thyroid lesions: A two year prospective study in the malwa region of central India
}

\author{
Chakrabarti PR ${ }^{1}$, Mishra P², Chakrabarti $S^{3}$, Patidar $R^{4}$, Jain $A^{5}$, Gupta $P^{6}$ \\ ${ }^{1}$ Dr Preeti Rihal Chakrabarti, Department of Pathology, Assistant Professor, ${ }^{2}$ Dr Poonam Mishra, Department of \\ Pathology, Assistant Professor, ${ }^{3}$ Dr Chakrabarti Suvadip, MCH Department of Surgical Oncology, Assistant Professor, \\ ${ }^{4}$ Dr Rashmi Patidar, Junior Resident, ${ }^{5}$ Dr Akansha Jain, Junior Resident, ${ }^{6}$ Dr Priyanka Gupta, MBBS, Junior Resident. \\ All are affiliated with Sri Aurobindo Medical College and PG Institute, Indore, Madhya Pradesh.
}

Address for Correspondence: Dr Preeti Rihal Chakrabarti, Flat 404, Akanksha Apartments, Sri Aurobindo Medical College and PG Institute, Indore, Madhya Pradesh.

\begin{abstract}
Background: Thyroid lesions are commonly encountered in daily clinical practice. However, excision of thyroid lesions is associated with risk. Hence an effective preliminary test is needed to avoid unnecessary surgery. An assessment of thyroid lesion by FNAC has proved to provide early diagnosis and hence helps in avoiding invasive surgery. Aims and Objectives: The purpose of present study was to study various cytomorphological features of thyroid lesions in the tertiary teaching hospital of Malwa region with respect to age, sex and to categorize them into neoplastic and nonneoplastic lesions. Materials and methods: FNAC was performed on patients who presented with thyroid swelling in department of pathology of Sri Aurobindo Medical College and PG Institute, from $1^{\text {st }}$ January 2014 to $31^{\text {st }}$ December 2015. Results: Out of 186 patients in our study group 161(86.56\%) were benign, 23(12.37\%) were malignant and 2 were inconclusive. Benign follicular lesion 108 (67\%) was commonest under non-neoplastic category and follicular neoplasm $19(82.6 \%)$ under neoplastic category. Male to female ratio was 1:4. Conclusion: FNAC plays an important role in thyroid lesions as it is safe, cost effective and also helps in selections of patients for surgery, thus minimizing risk associated with surgery.
\end{abstract}

Keywords: FNAC, Thyroid, Benign follicular lesions, Lymphocytic thyroiditis.

\section{Introduction}

Thyroid swelling is commonest presentation of patients encountered in FNAC OPD. FNAC of thyroid is noninvasive, cost effective, efficient and time saving procedure with minimal risk and early diagnosis. FNAC is usually considered as 1st line of investigation followed by ultrasound examination, thyroid function and antibody level [1]. According to projection from various studies on thyroid diseases it has been estimated that about 40 million people in India suffer from thyroid diseases. It has also been reported that endemic goiter is common in all over India and not just from Himalayan and Sub-Himalayan region [2]. The main purpose of FNAC in thyroid lesions is to differentiate between neoplastic and non-neoplastic lesions and avoid unnecessary surgery [3].

Manuscript received: $24^{\text {th }}$ Feb 2016

Reviewed: $04^{\text {th }}$ March 2016

Author Corrected: $14^{\text {th }}$ March 2016

Accepted for Publication: $24^{\text {th }}$ March 2016

\section{Aims and Objectives}

1) To study the various cytomorphological spectrum of thyroid lesion in the tertiary teaching hospital of Malwa region.

2) To study the thyroid lesions with respect to age and sex.

3) To categorize as non-neoplastic and neoplastic lesion and thus avoiding unnecessary surgery.

4) To highlight the limitations and pitfalls of FNAC.

\section{Materials and Method}

Our study was prospective study carried out in the Department of Pathology, Sri Aurobindo Medical College and Post Graduate Institute, Indore, Madhya Pradesh from $1^{\text {st }}$ January 2014 to $31^{\text {st }}$ December 2015. FNAC were performed in 186 patients, presented with thyroid swelling referred from various departments. Inclusion criteria consisted of all the cases of palpable 
thyroid swelling and non-palpable lesions through ultrasound and CT guided FNAC. Exclusion criteria consisted of all the cases having neck swelling other than thyroid. A detailed clinical history pertaining to thyroid profile, ultrasonography, previous surgery, etc were noted.

Patients were clinically examined for thyroid swelling and features related to consistency, type of enlargement (diffuse/ nodular), movement on deglutition and protrusion of tongue. FNAC of thyroid swelling was performed under aseptic precautions using 23-24 G needle. Patients were made to lie down flat with pillow under the shoulder, head falling back with neck extended. Patients were asked not to speak or deglutinate during procedure. Needle was inserted in the gland, to and fro movement of needle was done, with minimal negative pressure, material was aspirated and expelled on slides.

Smears were made and slides were air dried and stained by Giemsa stain and alcohol fixed slides were stained by PAP stain. In fluid aspirates material was centrifuged and slides were prepared with sediment. Repeat FNAC was carried out in case of hemorrhagic aspirates. Thyroid profile reports were available of 162 patients and correlated respectively.

\section{Results}

Out of 186 cases of thyroid swelling 151 (81.1\%) were females and 35 (18.8\%) were males (M: F ratio- 1:4). The age ranged from 5 to 72 years. Among the diagnostic outcomes, 161 (86.56\%) were non-neoplastic (Benign), 23 (12.37\%) cases were malignant and 2 cases were Inconclusive. [Table1]

Table 1: Distribution of various thyroid lesions

\begin{tabular}{|l|l|l|}
\hline Diagnosis & $\begin{array}{l}\text { No of Cases } \\
(\mathbf{n = 1 8 6 )}\end{array}$ & $\begin{array}{l}\text { Percentage } \\
(\mathbf{\%})\end{array}$ \\
\hline Non-neoplastic thyroid lesions & 161 & 86.56 \\
\hline Neoplastic thyroid lesions & 23 & 12.37 \\
\hline Inconclusive & 02 & 1.08 \\
\hline
\end{tabular}

Of 161 benign lesions, Benign follicular lesion (Colloid/Nodular/Adenomatoid) were commonest 108(67.0\%) followed by lymphocytic thyroiditis $23(14.2 \%)$ [Table 2]. Both Goitre (32 cases) and lymphocytic thyroiditis (7 cases) were most commonly encountered in $4^{\text {th }}$ decade [Table 3].

Table 2: Cyto-morphological spectrum of various thyroid lesions

\begin{tabular}{|l|l|l|}
\hline Diagnosis & $\begin{array}{l}\text { No of Cases } \\
(\mathbf{n = 1 8 6 )}\end{array}$ & $\begin{array}{l}\text { Percentage } \\
(\mathbf{\%})\end{array}$ \\
\hline Colloid cyst & 16 & 8.60 \\
\hline Benign follicular lesion & 108 & 58.10 \\
\hline Lymphocytic thyroiditis & 23 & 12.37 \\
\hline Hashimoto thyroiditis & 10 & 5.38 \\
\hline Granulomatous thyroiditis & 04 & 2.15 \\
\hline Follicular neoplasm & 19 & 10.22 \\
\hline Papillary carcinoma & 02 & 1.07 \\
\hline Medullary carcinoma & 01 & 0.54 \\
\hline Anaplastic carcinoma & 01 & 0.54 \\
\hline Inconclusive & 02 & 1.07 \\
\hline
\end{tabular}

Of 23 neoplastic lesions, follicular neoplasm was the commonest $19(82.6 \%)$, followed by papillary carcinoma $2(8.6 \%)$. Follicular neoplasm was most commonly encountered in $5^{\text {th }}$ Decade $(5$ cases $)$ and papillary carcinoma in $3^{\text {rd }}$ decade $(2$ cases) [Table 3]. Two cases were under the category of inconclusive where diagnosis of follicular neoplasm/nodular goitre was given. 
Table 3: Age wise distribution of Thyroid lesions

\begin{tabular}{|c|c|c|c|c|c|c|c|c|}
\hline \multirow[t]{2}{*}{ Diagnosis } & \multicolumn{8}{|c|}{ Age groups (yrs) } \\
\hline & $0-10$ & $11-20$ & $21-30$ & $31-40$ & $41-50$ & $51-60$ & $61-70$ & $>70$ \\
\hline Colloid cyst & 01 & 02 & 02 & 07 & 02 & 00 & 01 & 01 \\
\hline Benign follicular lesions & 01 & 03 & 26 & 30 & 32 & 10 & 05 & 01 \\
\hline $\begin{array}{l}\text { Lymphocytic } \\
\text { Thyroiditis }\end{array}$ & 00 & 06 & 04 & 07 & 01 & 04 & 01 & 00 \\
\hline Hashimoto thyroiditis & 00 & 00 & 06 & 04 & 00 & 00 & 00 & 00 \\
\hline $\begin{array}{l}\text { Granulomatous } \\
\text { thyroiditis }\end{array}$ & 01 & 00 & 00 & 01 & 02 & 00 & 00 & 00 \\
\hline Follicular neoplasm & 00 & 02 & 03 & 02 & 05 & 04 & 03 & 00 \\
\hline Papillary carcinoma & 00 & 00 & 02 & 00 & 00 & 00 & 00 & 00 \\
\hline Medullary carcinoma & 00 & 00 & 00 & 00 & 00 & 01 & 00 & 00 \\
\hline Anaplastic carcinoma & 00 & 00 & 00 & 00 & 00 & 00 & 01 & 00 \\
\hline Inconclusive & 00 & 00 & 00 & 01 & 00 & 01 & 00 & 00 \\
\hline Total & 03 & 13 & 43 & 52 & 42 & 20 & 11 & 02 \\
\hline
\end{tabular}

\section{Discussion}

Thyroid Lesions are observed in $4-7 \%$ of the population and affect women more commonly than men. Excision of all the thyroid lesion is impracticable and associated with risks.[4,5] Hence, an effective screening test is needed to avoid unnecessary surgery. The diagnosis of thyroid lesions using aspiration cytology was first reported by Mortin and Ellis in 1930[6]. FNAC has become extremely valuable and is recommended as first choice of investigation for evaluation of thyroid lesions [7]. It has decreased the number of patients who underwent surgical treatment by $25-30 \%$, thus increasing the percentage of malignancy in operated group of patients [8].

In present study, FNAC of thyroid lesion was performed in 186 patients. The age of patients ranged from 5 years to 72 years with peak incidence in $4^{\text {th }}$ decade which was in concordance with previous studies $[9,10]$. Females outnumbered males with ratio of $4: 1$ which was consistent with other studies $[10,11,12]$.

Benign follicular lesions (Nodular goitre/ Colloid goitre) formed majority of the cases in the present study with peak incidence in 4th decade. Most of these patients presented with nodular or diffuse swelling and were euthyroid. Similar findings were also observed in other studies [13,7]. Cytological examination revealed abundant colloid admixed with monolayered sheets of hyperplastic and involution follicular epithelial cells, foamy macrophages, bare nuclei [Figure1].

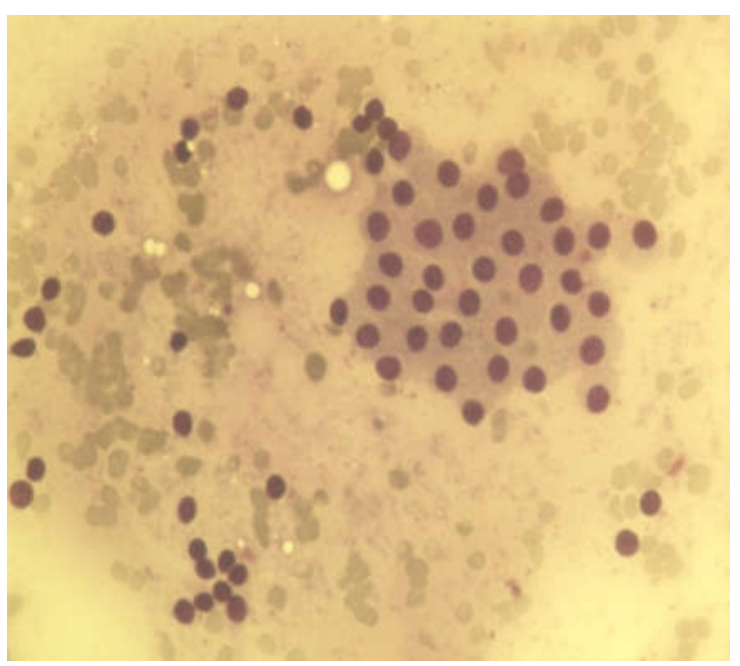

Fig-1: High pow er view of colloid goitre displaying sheets of follicular epithelial cells (Pap- $400 \mathrm{X}$ )

Following colloid goitre, thyroiditis (lymphocytic) was the next most common lesion seen. Majority of the patients were in $2^{\text {nd }}$ and $4^{\text {th }}$ decade of life. Cytological examination revealed dense infiltration by lymphocytes, admixed with follicular epithelial cells and scant colloid [Fig 2]. However in another study, Hashimoto thyroiditis was common lesion following colloid goitre [13]. Cytological examination of Hashimoto thyroiditis revealed predominantly hurthle change with lymphocytic infiltrate [Fig3]. In few cases of thyroiditis, initial aspirate did not yield enough material by non- 
aspiration technique; hence aspiration was carried out by giving negative suction with syringe. This was mainly due to solidification of thyroid gland by dense infiltration by lymphocytes and decreased vascularity compared to other thyroid lesions [14].

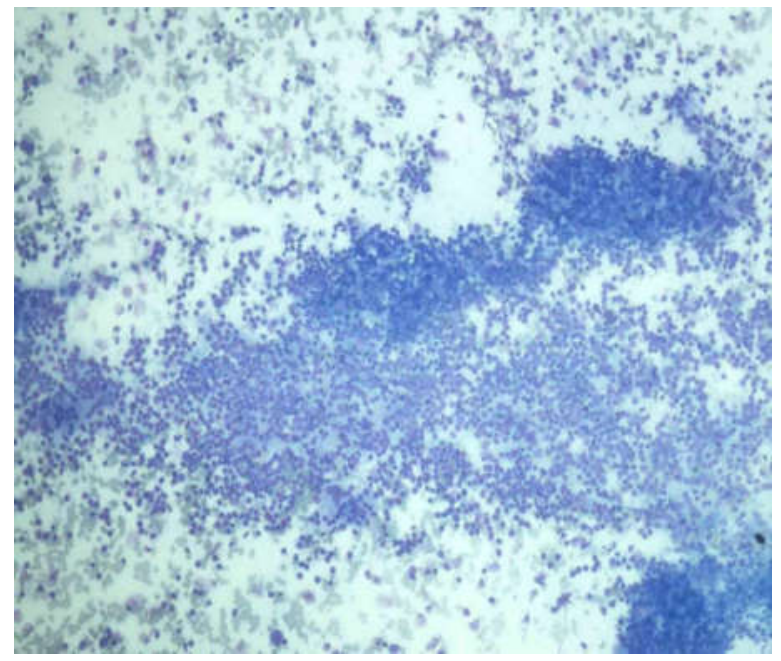

Fig-2: Low power view of lymphocytic thyroiditis showing numerous lymphocytes admixed with follicular epithelial cells.(Giemsa-100 X)

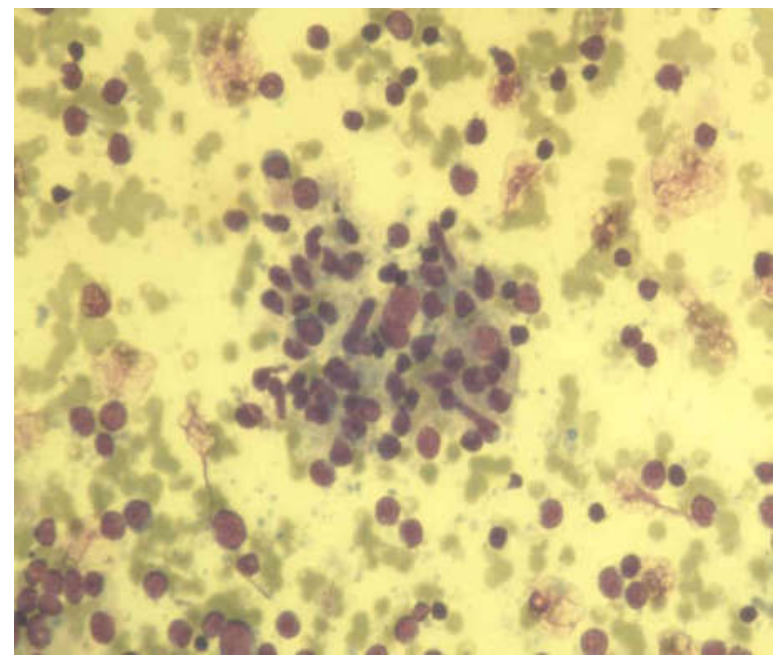

Fig-3: High power view of Hashimoto's thyroiditis displaying hurthle cell change with lymphocytic infiltration in follicular cells. (Giemsa $\mathbf{- 4 0 0} \mathrm{X}$ )

In present study, out of 23 neoplastic thyroid lesions, maximum no of cases $19(82.6 \%)$ were reported as follicular neoplasm followed by papillary carcinoma $2(8.6 \%)$. Cytological examination of follicular neoplasm revealed high cellularity with microfollicles forming repetitive follicular pattern with minimal anisonucleosis, nuclear overcrowding at places with scant to absent colloid[Fig 4]. One of the pitfalls of FNAC is marked cellularity. Loss of cohesion with increased cellularity may be present in hyperplastic nodule, adenoma or in carcinoma. It is also, difficult to differentiate follicular adenoma from carcinoma on the cytological assessment because cytological examination cannot assess the criteria for vascular and capsular invasion or of intrathyroid spread [15].

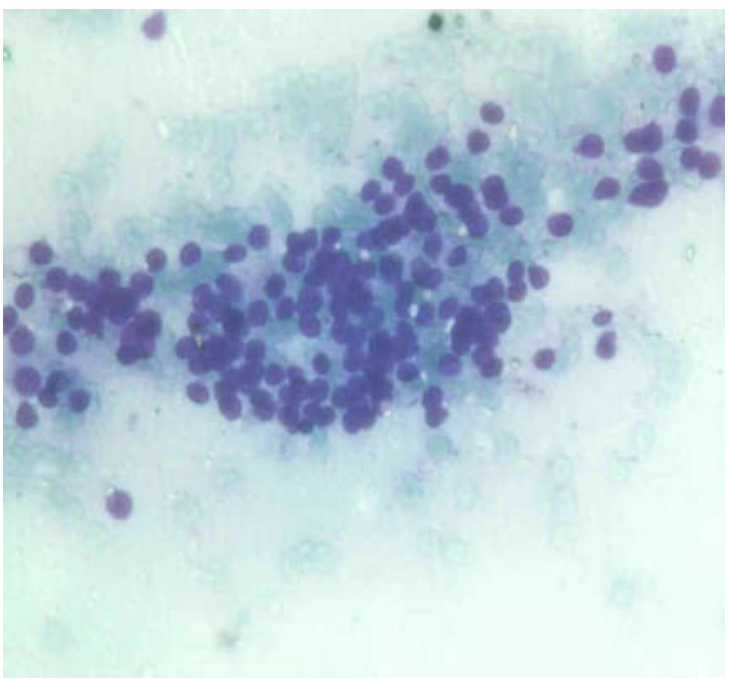

Fig-4: High power view of follicular neoplasm showing monomorphic microfollicular repetitive pattern. (Giemsa-400X)

Two cases in present study were inconclusive (colloid goitre/ follicular neoplasm). Cytological differentiation between follicular neoplasm and colloid goiter is sometimes difficult [16]. Probably, aspiration in these cases was done from rich cellular macrofollicular area with colloid. However, few important distinguishing features that favors follicular neoplasm over colloid goiter are nuclear crowding, nuclear overlapping, repetitive uniform follicular pattern, syncytial clusters, microfollicular structures, scanty or no colloid, although none of them is conclusive [17].

Proper sampling from a representative site is important for a correct diagnosis. Most authors recommended preparation of 4-6 smears from different areas of nodule. Strict criteria for specimen adequacy could help to reduce erroneous diagnosis [18]. Ultrasound guided FNAC results in better sampling, resulting in lower rate of non-diagnostic smears and high accuracy [19]. In present study, two cases of papillary carcinoma were reported in female patients in $3^{\text {rd }}$ decade. These patients 
gave history of slow growing thyroid swelling, associated with pain, discomfort and hoarseness of voice.

Cytological examination revealed high cellularity, syncytial sheets and clusters of follicular epithelial cells showing nuclear grooves, intranuclear cytoplasmic inclusions with scanty colloid[Fig 5]. One case each of medullary and anaplastic carcinoma was reported in $6^{\text {th }}$ decade. Cytological examination of anaplastic carcinoma revelead bizarre pleomorphic tumor cells with necrotic material [Fig 6].

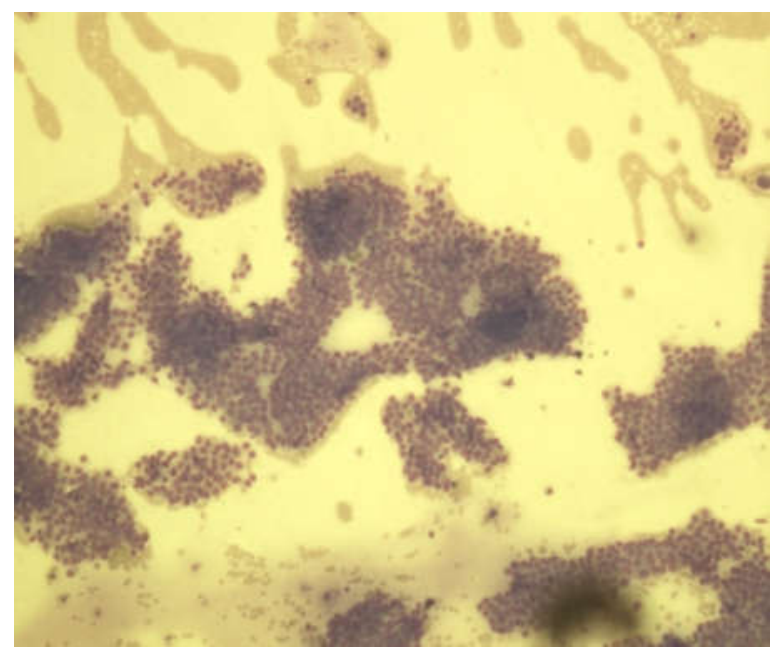

Fig 5: Low power view of papillary carcinoma showing papillary fronds.(Pap-100 X)

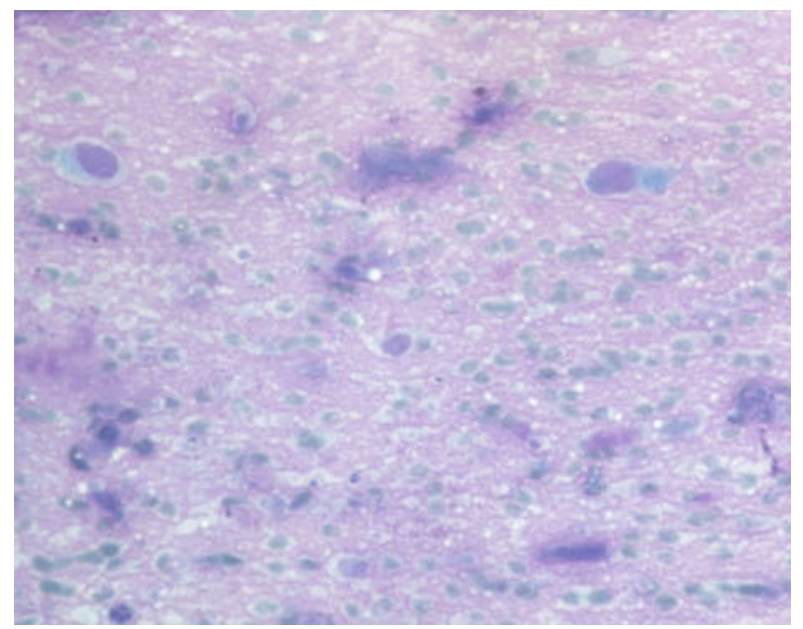

Fig 6: High power view of anaplastic carcinoma showing bizarre tumor cells with necrosis.(Giemsa: $400 \mathrm{X}$ )

A comparative study of FNAC with isotope scanning with I-131 scintiography found FNAC to be more specific than sensitive whereas thyroid isotope scan is more sensitive than specific in detecting thyroid malignancy. Therefore, FNAC should be adopted as an initial investigation of thyroid disease in all tertiary hospitals.[2]

\section{Conclusion}

Thus, with present study we conclude FNAC is safe, less invasive preliminary investigation of choice in thyroid lesions which helps in better differentiation between neoplastic and non-neoplastic lesions and hence minimizes surgical burden. Non-neoplastic thyroid lesions were commonly encountered in our study which was consistent with other studies.

\section{Funding: Nil, Conflict of interest: None.} Permission of IRB: Yes

\section{References}

1.La Rosa GL, Belfiore A, Giuffrida D, Sicurella C, Ippolito O, Russo G, et al. Evaluation of fine needle aspiration biopsy in preoperative selection of cold thyroid nodules. Cancer 1991;67:2137-41

2.Unnikrishnan AG, Menon UV. Thyroid disorders in India: An epidemiological perspective. Indian J Endocr Metab 2011;15:78-81

3. Gabalec F, Cap J, Ryska A, Vasatko T, and Ceeova V. Benign fine needle aspiration cytology of thyroid nodule: to repeat or not to repeat? European Journal of Endocrinology 2009;16:933-37

4. Abu-Nema T, Ayash K, Tibblin S : Role of aspiration biopsy cytology in the diagnosis of cold solitary thyroid nodules. Br J Surg 1987;74:203

5.Tunridge WM : The spectrum of thyroid disease in a community. The Wicham survey. Clin Endocrinol 1997; 17:481-493

6. Mangshetty SS, Jewargikar R, Andola SK. Fine needle aspiration cytology of 220 Thyroid lesions with histopathological correlation. Int $\mathrm{J}$ Res Health Sci 2014;2:243-53.

7. Sengupta A, Pal R, Kar S, Zaman FA, Senguota S, Pal S. Fine needle aspiration cytology as the primary diagnostic tool in thyroid enlargement. J Nat Sc Biol Med 2011;2:113-118 
8. Yassa L, Cibas ES, Benson CB, Frates MC, Doubilet PM, Gawande AA,et al. Long term assessment of a multidisciplinary approach to thyroid nodule diagnostic evaluation. Cancer 2007;111:508-16

9. Handu U, Garg S, Mohan H, Nagarkar N. Role of the fine needle aspiration cytology in diagnosis and management of thyroid lesions: A study on 434 patients. J cytol 2008;25:13-7

10.Jogai S, AI-Jassar A, Temmim L, Dey P, Adesina AO, Amanguno HG. Fine needle aspiration cytology of the thyroid: A cytohistological study with evaluation of discordant cases. Acta Cytol 2005;49:483-8

11.Jain S, Nayak R, Totade S, Shukla N. Clinicopathological correlation of thyroid swellings. Int J Med Res Rev 2014;2:553-60

12.Bamanikar S, Soraisaham $P$, Jadhav S, Kumar H, Jadhav P, Bamanikar A. Cyto-histology correlation and clinical correlation of thyroid gland lesions: A 3 year study in tertiary hospital. Clin Cancer Investig J 2014;3:208-12

13. Mangshetty SS, Jewargikar R, ASK. Fine Needle Aspiration Cytology of 220 Thyroid Lesions. Histopathological correlation. Int $\mathrm{J}$ Res Health Sci $2014 ; 2: 243-53$

14. Chand N, Bedi S, Kaur N, Gulati B, Sharma J, Bajwa D, Garg LN. Clinico-Cytological Spectrum Of Thyroid Mass Lesions Using FNAC And Corellating Biopsy. NJIRM 2015; 6: 84-89
15. Mittal A, Ahmad F, Dutta S, Nizammudin S, Awasthi S, Kumar A, Vyas P. Use and Accuracy of Fine Needle Aspiration Cytology in Thyroid Lesion: Our Experience in a Tertiary Teaching Hospital in North India. Int J Sci Stud 2015;3:95-100.

16.Orell SR, Sterrett GF, Whitaker D. Thyroid. In: Fine Needle Aspiration Cytology. $4^{\text {th }}$ ed. Philadelphia: Churchill Livingstone;2005.p.125-64.

17.Gamboa-Dominguez A, Candanedo-Gonzalez F, Uribe- Uribe NO, Angeles-Angeles A. Tall Cell variant of papillary thyroid carcinoma. A cytohistologic correlation, Acta Cytol 1997;41:672-6.

18. Yeh MW, Demircan O, Iturate P, Clark OH. Falsenegative fine-needle aspiration cytology results delay treatment and adversely affect outcome in patients with thyroid carcinoma. Thyroid 2004;14:207-15

19. Bellantone R, Lombardi CP, Raffaelli M, Traini E, De Crea C, Rossi ED, et al. Management of cystic or predominantly cystic thyroid nodules:The role of ultrasound-guided fine-needle aspiration biopsy. Thyroid 2004;14:43-7

20. Basharat R, Bukhari MH, Saeed S, Hamid T. Comparison of Fine Needle Aspiration Cytology and Thyroid Scan in Solitary thyroid Nodule. Pathology Res Int 2011;2011:754041.doi:10.4061/2011/754041

\section{How to cite this article?}

Chakrabarti PR, Mishra P, Chakrabarti S, Patidar R, Jain A, Gupta P. Trends in Cytomorphological Study of Thyroid lesions: A two year prospective study in the malwa region of central India: Int J Med Res Rev 2016;4(3):450-455. doi: 10.17511/ijmrr.2016.i03.29. 